\title{
The Effect of Heat Waves on Ambulance Attendances in Brisbane, Australia
}

\author{
Lyle R. Turner, $\mathrm{PhD} ;{ }^{1}$ Des Connell, $\mathrm{PhD} ;^{2}$ Shilu Tong, $\mathrm{PhD}^{1,3}$
}

1. School of Public Health and Social Work, Institute of Health and Biomedical Innovation, Queensland University of Technology, Brisbane, Australia

2. School of Environment, Griffith University, Brisbane, Australia

3. School of Public Health, Anhui Medical University, Hefei, Anhui, China

Correspondence:

Shilu Tong, $\mathrm{PhD}$

School of Public Health and Social Work

Institute of Health and Biomedical Innovation

Queensland University of Technology

Victoria Park Road, Kelvin Grove, QLD 4059, Australia

E-mail: s.tong@qut.edu.au

Conflicts of interest: The authors have no disclosures or conflicts of interest to report.

Keywords: climate change; Emergency Medical Services; heat wave

Abbreviations:

dfs: degrees of freedom

$\mathrm{NO}_{2}$ : nitrogen dioxide

$\mathrm{O}_{3}$ : ozone

$\mathrm{PM}_{10}$ : particulate matter smaller than $10 \mu \mathrm{m}$ QAS: Queensland Ambulance Service

Received: November 29, 2012

Revised: February 27, 2013

Accepted: March 10, 2013

Online publication: August 28, 2013

doi:10.1017/S1049023X13008789

\section{Abstract}

Introduction: Heat waves have significant impacts on mortality and morbidity. However, little is known regarding effects on pre-admission health outcomes such as ambulance attendances, particularly in subtropical regions.

Problem: This study investigated both main temperature effects and the added effects of heat waves on ambulance attendances in Brisbane, a subtropical city in Australia.

Methods: Daily data relating to 783,935 ambulance attendances, along with data on meteorological variables and air pollutants, were collected for the period 2000-2007. Ambient temperature (main) effects were assessed using a distributed lag nonlinear approach that accounted for delayed effects of temperature, while added heat wave effects were incorporated separately using a local heat wave definition. Effect estimates were obtained for total, cardiovascular and respiratory attendances, and different age groups.

Results: Main effects of temperature were found for total attendances, which increased by $50.6 \%(95 \% \mathrm{CI}, 32.3 \%-71.4 \%)$ for a $9.5^{\circ} \mathrm{C}$ increase above a reference temperature of $29^{\circ} \mathrm{C}$. An added heat wave effect on total attendances was observed $(18.8 \%$; $95 \%$ CI, 6.5\%-32.5\%). Significant effects were found for both respiratory and cardiovascular attendances, particularly for those aged 65 and above.

Conclusion: Ambulance attendances can be significantly impacted by sustained periods of high temperatures, and are a valid source of early detection of the effects of extreme temperatures on the population. The planning of ambulance services may need to be adapted as a consequence of increasing numbers of heat waves in the future. Ambulance attendance data also should be utilized in the development of heat warning systems and climate change adaptation strategies.

Turner LR, Connell D, Tong S. The effect of heat waves on ambulance attendances in Brisbane, Australia. Prehosp Disaster Med. 2013;28(5):482-487.

\section{Introduction}

Extreme temperatures have been found to have a detrimental effect on human health, with such impacts set to increase as a result of climate change. ${ }^{1}$ In particular, the effects of extreme heat consistently have been observed to impact health, ${ }^{2}$ with high temperatures associated with increased adverse health outcomes for cardiovascular, respiratory, and other chronic diseases. ${ }^{3,4}$

Heat waves are particularly dangerous, in that prolonged periods of high temperature can pose serious threats to health, particularly for vulnerable subgroups. ${ }^{5,6}$ During extended periods of high ambient temperature, the body's thermoregulatory ability can be impaired, ${ }^{2,7}$ particularly in the elderly, who have higher sweating thresholds and therefore a reduced capacity to cool down. This can place increased stress on vital organs, leading to susceptibility to morbidity or mortality due to heat stroke or pre-existing conditions. ${ }^{8}$ In light of future climate change projections of increasing frequency and intensity of heat waves, ${ }^{9}$ it is imperative to better understand the health impacts of heat waves in order to inform mitigation strategies that can minimize risks to public health. ${ }^{10}$

There has been a substantial amount of research examining the effects of hot temperatures and heat waves on mortality. ${ }^{2,11-13}$ Impacts on morbidity, however, have received less attention, with studies concentrating on emergency or hospital admissions. ${ }^{14-17}$ The effects of heat waves on different morbidities have been found to vary by both location and duration. ${ }^{18,19}$ The relationship between temperature and prehospital health outcomes such as ambulance attendances (also referred to as ambulance interventions or call-outs, where emergency care is given to those with acute health problems) has recently received 
increasing attention, particularly given the ability of such data to be used for the rapid detection of heat impacts. ${ }^{20,21}$ Effects have been found to depend on local climate and the particular condition requiring attendance, with some studies in Japan showing minimal heat effects. ${ }^{22-24}$ Studies from Canada observed increases for both all-cause $^{25}$ and heat-related attendances ${ }^{26}$ on hot days. A study of ambulance dispatches throughout the Emilia-Romagna region of Italy also showed a significant effect of hot temperatures on total, cardiovascular and respiratory attendances. ${ }^{27}$

A Swiss study ${ }^{28}$ examining the effects of the 2003 European heat waves found sharp increases in ambulance requests, particularly by those above 65 years of age, with the highest number of excess attendances (attendances above the expected value) during a heat wave recorded in that year. Similarly, studies of heat wave periods in Adelaide, Australia during 1993-2006 ${ }^{29}$ and $2008-2009^{30}$ found increased numbers of attendances for allcause, assault, cardiac and respiratory conditions. Another study in Sydney, Australia observed increases in all-cause attendances due to a 2011 heat wave, with the largest effect experienced by those aged 75 and above. ${ }^{20}$

Little is known about whether heat waves increase the demand on ambulance services in tropical and subtropical climates, as residents in those regions are well accustomed to hot weather. This study examined if there was an increase in ambulance attendances due to heat wave episodes experienced between 2000 and 2007 in Brisbane, the capital city of Queensland, Australia, located on its eastern coast $\left(27^{\circ} 30^{\prime}\right.$ south and $153^{\circ} 00^{\prime}$ east). The city has a subtropical climate, with mild winters and hot summers.

\section{Methods \\ Data}

Daily data of meteorological and air pollution variables, along with ambulance attendance records in Brisbane, Australia, were obtained for the period from January 1, 2000 through December 31, 2007.

Ambulance attendance data were supplied by the Queensland Ambulance Service (QAS), the primary service providers of outof-hospital emergency care and ambulance transport in Queensland. The data were obtained in a de-identified format from the ambulance information management system and consisted of individual cases, with each record containing the attendance date, the location of the attendance event (specified in this case by postcode), as well as the age and gender of the attendee. Each record also contained a coded summary of both the general nature of the attendance event (recorded pre-attendance by the phone operator taking the call, post 2005 only) and the final assessment of the attendance, recorded by the attending paramedic. Ethical approval was obtained from the Human Research Ethics Committee of the Queensland University of Technology prior to the dataset being obtained from the QAS.

Meteorological data were obtained from the Bureau of Meteorology, with daily observations of maximum temperature over 24 hours (after $9 \mathrm{AM}$ ) and relative humidity obtained over the study period. Data relating to a number of different air pollutants were obtained from the Department of Environment and Heritage Protection (formally the Department of Environment and Resource Management). The specific variables collected for inclusion in the analysis were hourly mean concentrations of ozone $\left(\mathrm{O}_{3}\right)$ and nitrogen dioxide $\left(\mathrm{NO}_{2}\right)$, along with particulate matter smaller than $10 \mu \mathrm{m}\left(\mathrm{PM}_{10}\right)$. Daily mean values were calculated for all air pollutants across eight monitoring stations; when a particular station lacked daily environmental data, the average across the remaining stations was calculated and used.

\section{Heat Wave Definition}

There are various definitions used to identify heat waves, and to date there has been no accepted definition that applies to all populations. ${ }^{31}$ Following previous studies conducted in Brisbane, ${ }^{18,32}$ a heat wave was defined as two or more consecutive days with a daily maximum temperature at or above $37^{\circ} \mathrm{C}$.

\section{Statistical Analysis}

To examine the association between heat waves and ambulance attendances, data were categorized by type of attendance. Specifically, daily numbers of events for groups of assessment codes related to total, cardiovascular and respiratory attendances were examined. To remove the influence of cold temperatures, the study period was restricted to the warm months of each year (October-March).

To examine both the effects of ambient temperature (main effects) and the added effects of heat waves, an over-dispersed Poisson regression model for daily attendance counts was used. ${ }^{19,33}$ The main and added effects were separated in the model, which was implemented in the following form:

$$
\begin{gathered}
Y_{t} \sim \text { Poisson }\left(\mu_{t}\right) \\
\log \left[E\left(Y_{t}\right)\right]= \\
\beta_{0}+n s\left(T_{t}, d f s=3, d f_{\text {lag }}=5\right) \\
+\beta_{1} H W_{t}+C O V_{t}
\end{gathered}
$$

Here $T_{t}$ denotes the daily maximum temperature, and $H W_{t}$ the heat wave indicator. To capture lagged effects in the ambient temperature-attendance relationship, daily maximum temperature was incorporated using a distributed lag nonlinear model, ${ }^{34}$ which allowed both nonlinear temperature and lagged effects (up to 10 days) to be modeled simultaneously. In this formulation, the effect was examined across varying maximum temperature and lag, and modeled using a natural cubic spline-natural cubic spline formulation, with three and five degrees of freedom (dfs), respectively.

Main effect estimates were obtained from the nonlinear function for $T_{t}$, which were presented as a percentage change in attendances due to a $9.5^{\circ} \mathrm{C}$ increase above $29^{\circ} \mathrm{C}$. This was the reference temperature at which the lowest number of attendances occurred, and the corresponding temperature increase was the difference between the average maximum temperature on heat wave days and this reference temperature.

The heat wave indicator identified those days that met the heat wave definition. The added effects, that is, those in excess of the main effects of ambient temperature, were estimated from the heat wave indicator coefficient, and were stated as a percentage change in attendances for heat wave days compared to non-heat wave days.

The model was adjusted for several covariates $\left(C O V_{s}\right)$, including humidity and atmospheric pollutants $\mathrm{O}_{3}, \mathrm{NO}_{2}$, and $\mathrm{PM}_{10}$, with each fitted using splines with four dfs. To model both within-summer seasonality and long-term trends, splines were fitted for day-of-season and year using four and two dfs, respectively. Throughout, the choices of $\mathrm{dfs}$ for the nonlinear functions were based on previous research. ${ }^{19,35}$ Both day-of-week and public holidays were incorporated as categorical variables in the model. 


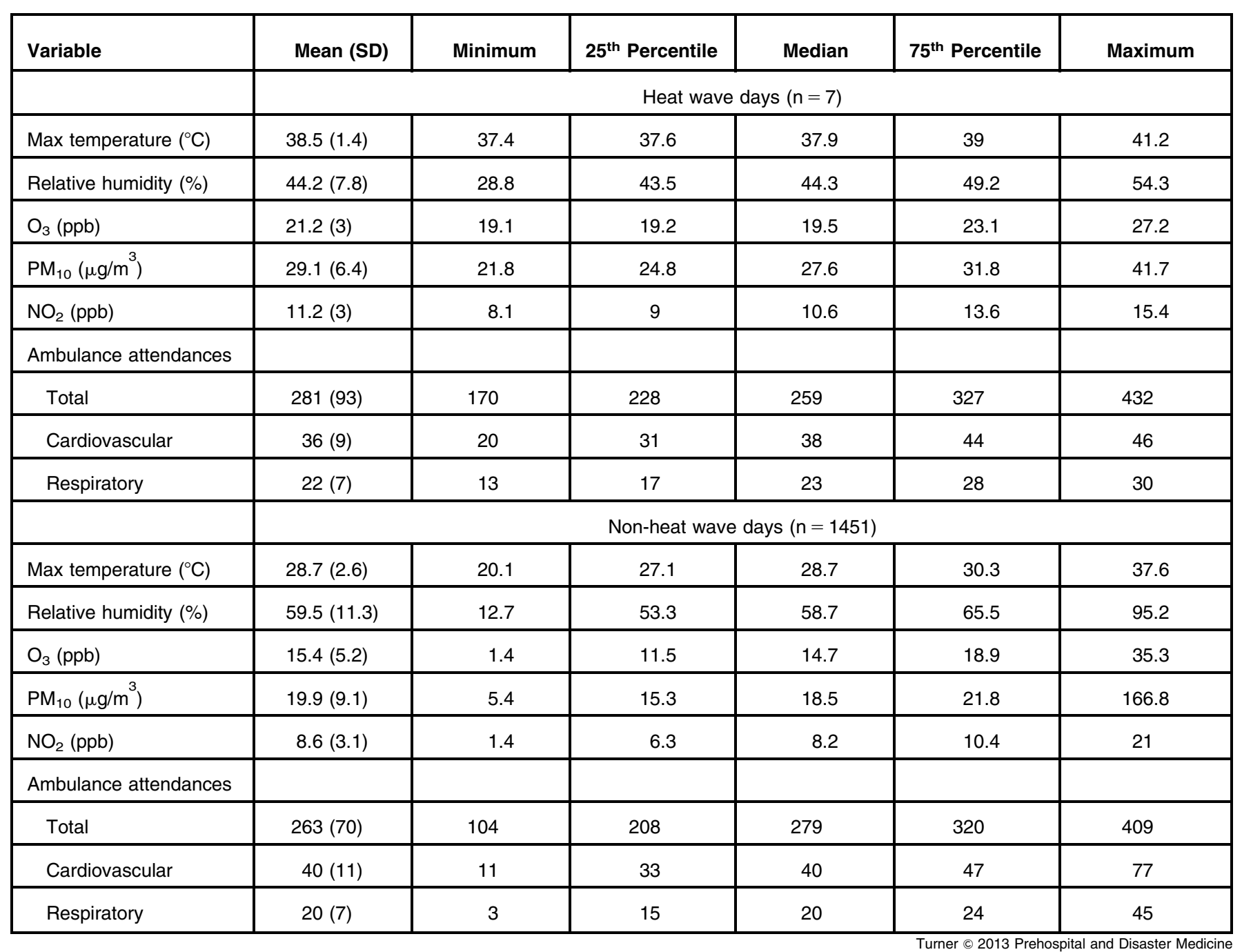

Table 1. Summary Statistics for Daily Ambulance Attendance (All Ages), Meteorological and Air Pollution Variables in Brisbane, 2000-2007

In the first instance, the data were analyzed using the primary heat wave definition $\left(37^{\circ} \mathrm{C}\right.$ for two or more days), across groups defined by attendance type (total, cardiovascular and respiratory) and age group (All ages, 15-64, 65-74, 75+). In order to conduct sensitivity analyses, the same model was applied for heat waves defined according to various percentiles of observed temperature. ${ }^{19,31}$ Specifically, heat waves were defined by considering temperatures above the $90^{\text {th }}, 95^{\text {th }}, 97^{\text {th }}$, and $99^{\text {th }}$ centiles. A "leave-one-out" regime also was used, with each heat wave being left out of the analysis in an iterative manner. All analyses were conducted in SAS V9.2 (SAS Institute Inc, Cary, North Carolina USA) and the R statistical package V2.12.2 (R Core Team, Vienna, Austria).

\section{Results}

The primary heat wave definition applied in this study was two or more consecutive days with a daily maximum temperature at or above $37^{\circ} \mathrm{C}$. Three such heat waves were found to have occurred over the study period: January 20-21, 2000; December 24-26, 2001; and February 21-22, 2004. The average maximum temperature was $38.5^{\circ} \mathrm{C}(\mathrm{SD}=1.4)$ during heat wave days, compared with $29.4^{\circ} \mathrm{C}(\mathrm{SD}=2.5)$ for non-heat wave days (Table 1). Average values for air pollutants $\left(\mathrm{O}_{3}, \mathrm{PM}_{10}\right.$ and $\left.\mathrm{NO}_{2}\right)$ all were increased during heat wave periods.

Over the study period, there were 783,935 ambulance attendances, with the mean number of attendances during heat wave days being $281(\mathrm{SD}=93)$, compared to 263 for non-heat wave days $(\mathrm{SD}=70)$. The mean number of respiratory attendances during heat waves was slightly above that of non-heat wave days; however mean numbers of cardiovascular attendances were lower during heat wave days compared with non-heat wave days.

Table 2 shows the estimated percentage increases in ambulance attendances for both the main effects and added heat wave effects. Across all ages, main temperature effects were observed for total (50.6\%; 95\% CI, 32.3\%-71.4\%) and respiratory (101.1\%; $95 \%$ CI, 34.0\%-201.9\%) attendances. The 15-64 age group showed a main effect for total attendances (33.2\%; 95\% CI, 11.4\%-59.2\%), and the $75+$ age group showed significant increases for total (85.4\%; 95\% CI, 49.6\%-129.7\%) and respiratory (162.8\%; 95\% CI, $32.8 \%-420.0 \%)$ attendances.

An added heat wave effect was observed for total (18.8\%; $95 \%$ CI, 6.5\%-32.5\%), cardiovascular (29.5\%; 95\% CI, 0.4\%-67.0\%) 


\begin{tabular}{|c|c|c|c|}
\hline $\begin{array}{l}\text { Attendance } \\
\text { Type }\end{array}$ & Age & Main Effect (\% increase, $\left.{ }^{a} 95 \% \mathrm{Cl}\right)^{b}$ & Added Effect (\% increase, $95 \% \mathrm{Cl})^{\mathrm{b}}$ \\
\hline \multirow[t]{3}{*}{ Total } & $15-64$ & $33.2(11.4,59.2)$ & $-2.8(-17.0,13.7)$ \\
\hline & $65-74$ & $34.1(-5.2,89.8)$ & $87.9(44.5,144.4)$ \\
\hline & $75+$ & $85.4(49.6,129.7)$ & $32.7(11.8,57.5)$ \\
\hline \multirow[t]{3}{*}{ Cardiovascular } & $15-64$ & $-18.8(-50.6,33.3)$ & $31.3(-15.3,103.6)$ \\
\hline & $65-74$ & $-12.5(-56.3,75.3)$ & $163.7(56.0,345.8)$ \\
\hline & $75+$ & $13.9(-26.7,77.1)$ & $-10.7(-39.1,31.0)$ \\
\hline \multirow{2}{*}{ Respiratory } & $75+$ & $162.8(32.8,420.0)$ & $9.5(-37.6,91.9)$ \\
\hline & Total & $101.1(34.0,201.9)$ & $48.7(6.4,107.7)$ \\
\hline
\end{tabular}

Table 2. Main and Added Effects of Heat Waves on Ambulance Attendances in Brisbane, 2000-2007

${ }^{\text {a}}$ Effect of average maximum temperature during heat wave days relative to $29^{\circ} \mathrm{C}$.

${ }^{\mathrm{b}}$ Numbers in bold are significant.

and respiratory (48.7\%; 95\% CI, 6.4\%-107.7\%) attendances. In terms of specific age groups, an added heat wave effect was found for total and respiratory attendances, with significant effects for the 65-74 and 75+ age groups. The 65-74 age group experienced added heat wave effects for total $(87.9 \%$; $95 \%$ CI, 44.5\%-144.4\%), cardiovascular (163.7\%; 95\% CI, 56.0\%$345.8 \%)$ and respiratory (127.3\%; 95\% CI, $14.7 \%-350.3 \%)$ attendances, while the $75+$ age group experienced added heat wave effects for total $(32.7 \%$; 95\% CI,11.8\%-57.5\%) attendances.

A sensitivity analysis was conducted, comparing the local heat wave definition with four additional definitions using the $90^{\text {th }}, 95^{\text {th }}, 97^{\text {th }}$ and $99^{\text {th }}$ centiles of daily maximum temperature (see online supplemental material). There was marked variation in both the number (3-65 heat waves) and duration (3-12 days) of heat waves under the various definitions, with added effects generally increasing with higher percentiles of temperature.

\section{Discussion}

The results of this study show that, even in a subtropical climate, heat events can have a large impact on the health of the local population. Heat waves were found to contribute to increases in ambulance attendances for total, cardiovascular and respiratory categories, in addition to those due to ambient temperature increases. These additional effects were particularly apparent in people aged 65 years and above, with heat wave effects differing between age groups and attendance categories.

These results are broadly consistent with several other studies. For example, in Ticino, Switzerland during 2003, ${ }^{28}$ an increase of $51 \%$ over expected attendance numbers was observed during the first of three heat waves, and $21 \%$ over all three $(65$ years of age and over). As opposed to the present study, a lower temperature threshold was used to define heat waves; which is likely to be explained by differences in population adaptation. Two South
Australian studies ${ }^{29,30}$ found total ambulance attendances increased by 4\% (95\% CI, 2\%-7\%) during heat waves from 1996 through 2006, and by $10 \%$ (95\% CI, 3\%-17\%) and 16\% (95\% CI, 8\%-24\%) during the 2008 and 2009 heat waves, respectively. The latter study also found that cardiac attendances increased by $10 \%$ (95\% CI, 1\%-20\%) and 13\% (95\% CI, 3\%-23\%) during the 2008 and 2009 heat waves, respectively. Similar results were also found during the Sydney heat waves of $2011,{ }^{20}$ with all-cause attendances increasing by $14 \%$ (95\% CI, 11\%-16\%). The results of the present study indicate greater heat wave effects than those observed in other studies, which could be a consequence of the substantially higher threshold used in the present study to define heat waves. However, comparable effects have been found when examining heat wave related morbidities such as emergency ${ }^{18}$ and hospital $^{36}$ admissions.

Heat waves can have a substantial effect on the health of vulnerable subgroups, particularly the elderly and frail. These individuals are at higher risk of morbidity or mortality as a consequence of heat exposure, ${ }^{35,37}$ due to a decreased ability of the body to compensate for higher temperatures, additional stress caused by other chronic health conditions (including dehydration), and potential alterations in the effect of medication. ${ }^{38}$ The results of this study support such observations, showing that during heat waves, conditions such as cardiovascular and respiratory diseases were associated with an increased numbers of ambulance attendances for older individuals, particularly those aged 65-74. While heat waves were found to affect total attendances in the $75+$ age group, no added effect was observed for either cardiovascular or respiratory attendances. The lack of effect for the elderly in these two attendance categories is consistent with previous studies, though the reasons for this remain unclear. ${ }^{29,30}$ One potential explanation is that this age group is likely to include a higher proportion of people who live in aged-care facilities, which 
are generally fitted with air-conditioners and provide a cooler, protective environment. $^{39}$

\section{Strengths and Limitations}

The study has a number of strengths. First, to the authors' knowledge, this is the first study to examine the effects of heat waves on ambulance attendances in a subtropical region. Second, a local heat wave definition was adopted, and in addition, a sensitivity analysis was conducted using different heat wave definitions. Finally, the study assessed separately both the main effects of ambient temperature and additional heat wave effects.

There are also some limitations to this study that should be acknowledged. First, only the intensity, and not the duration of the heat waves was considered. As it has been noted in other studies that heat wave duration can influence the extent of associated health effects, ${ }^{15,33}$ further analysis should be conducted that incorporates duration. Second, the method used to classify ambulance attendance category was more general than those used in medical facilities, as the codes are primarily for administrative use only. Along with practical limits of assessment in a nonhospital setting, an increased risk of misclassification necessitated the grouping of attendance conditions into the general groups of cardiovascular and respiratory attendances. It was also not possible to distinguish planned ambulance attendances (pre-booked ambulance transfers); however it is likely that such events were constant across the study period. Third, only data from one city was available for this study, so the results should be generalized with caution. Finally, there may be some exposure error in the data due to variations between the location of exposure measurements and attendances, as well as the fact that the attendance locations may not have corresponded to the locations where individuals received the majority of their exposure. However, given the high correlation found between temperature readings at different weather stations, such error should be minimal.

\section{Policy Implications}

Projected increases in both the frequency and intensity of heat waves imply that public health strategies must adapt in order to deal with greater heat-related impacts in the coming decades. This study adds to the currently limited research of the effects of extreme heat events on prehospital health outcomes, and makes

\section{References}

1. Haines A, Kovats RS, Campbell-Lendrum D, Corvalan C. Climate change and human health: impacts, vulnerability, and mitigation. Lancet. 2006;367: 2101-2109.

2. Basu R. High ambient temperature and mortality: a review of epidemiologic studies from 2001 to 2008. Environ Health. 2009;8:40.

3. Turner LR, Barnett AG, Connell D, Tong S. Ambient temperature and cardiorespiratory morbidity: a systematic review and meta-analysis. Epidemiology. 2012;23(4):594-606.

4. Ye X, Wolff R, Yu W, Vaneckova P, Pan X, Tong S. Ambient temperature and morbidity: a review of epidemiological evidence. Environ Health Perspect. 2012;120(1):19-28.

5. Poumadere M, Mays C, Le Mer S, Blong R. The 2003 heat wave in France: dangerous climate change here and now. Risk Anal. 2005;25(6):1483-1494.

6. Astrom DO, Forsberg B, Rocklov J. Heat wave impact on morbidity and mortality in the elderly population: a review of recent studies. Maturitas. 2011; 69(2):99-105.

7. Tong S, Ren C, Becker N. Excess deaths during the 2004 heatwave in Brisbane, Australia. Int J Biometeorol. 2010;54(4):393-400.

8. Anderson BG, Bell ML. Weather-related mortality: how heat, cold, and heat waves affect mortality in the United States. Epidemiology. 2009;20(2): 205-213. useful contributions to both the literature and policy development. The analysis of prehospital events, particularly those related to ambulance attendances, has the potential to identify serious heatrelated health events either prior to fatalities occurring, or for those events that do not directly lead to death. Comparing prehospital data with both hospital admission and mortality outcomes therefore could improve the ability of heat warning systems $^{40}$ to forecast heat-related health problems in the population prior to large numbers of fatalities. This research also informs the operation and future deployment of ambulance services, as it is critical that such services are delivered in an optimal fashion to meet the needs of vulnerable subgroups. ${ }^{41}$

It is important for policy makers to develop public health strategies to protect vulnerable groups such as the elderly and people with pre-existing medical conditions, who have been shown to be at increased risk of heat-related morbidity and mortality. ${ }^{36,42}$ This vulnerability is due partly to issues such as inadequate housing, poor capacity to maintain appropriate ambient temperatures, and a weakening physiological ability to stabilize the body temperature, factors that may be compounded by a general lack of awareness of appropriate heat-related health risks. ${ }^{43}$ Therefore, future research should examine where vulnerable groups are located, and how such demographic information can be incorporated effectively into surveillance systems. ${ }^{44}$

\section{Conclusion}

In this study, both the main effects of temperature and additional effects of heat waves on ambulance attendances in a subtropical climate were examined. The results show increased levels of ambulance attendance for older individuals (including the elderly) related to total and cardiovascular conditions. These findings stress the importance of adequately managing ambulance services in times of severe heat events, particularly due to the severe impacts that heat waves have on vulnerable subgroups such as the elderly and people with pre-existing medical conditions. These results may have significant implications in the development of heat warning systems and climate change adaptation strategies.

\section{Supplementary material}

To view supplementary material for this article, please visit http:// dx.doi.org/10.1017/S1049023X13008789

9. IPCC. Climate Change 2007: Synthesis Report. Contribution of Working Groups I, II and III to the Fourth Assessment Report of the Intergovernmental Panel on Climate Change. Geneva: Intergovernmental Panel on Climate Change (IPCC), 2007.

10. Huang C, Barnett AG, Wang X, Vaneckova P, FitzGerald G, Tong S. Projecting future heat-related mortality under climate change scenarios: a systematic review. Environ Health Perspect. 2011;119(12):1681-1690.

11. Hajat S, Kosatky T. Heat-related mortality: a review and exploration of heterogeneity. J Epidemiol Community Health. 2010;64(9):753-760.

12. Huang W, Kan H, Kovats S. The impact of the 2003 heat wave on mortality in Shanghai, China. Sci Total Environ. 2010;408(11):2418-2420.

13. Yu W, Mengersen K, Wang X, Ye X, Guo Y, Pan X, Tong S. Daily average temperature and mortality among the elderly: a meta-analysis and systematic review of epidemiological evidence. Int J Biometeorol. 2012;56(4): 569-581.

14. Hansen AL, Bi P, Ryan P, Nitschke M, Pisaniello D, Tucker G. The effect of heat waves on hospital admissions for renal disease in a temperate city of Australia. Int J Epidemiol. 2008;37(6):1359-1365.

15. Mastrangelo G, Fedeli U, Visentin C, Milan G, Fadda E, Spolaore P. Pattern and determinants of hospitalization during heat waves: an ecologic study. BMC Public Health. 2007;7:200. 
16. Knowlton K, Rotkin-Ellman M, King G, et al. The 2006 California heat wave: impacts on hospitalizations and emergency department visits. Environ Health Perspect. 2009;117(1):61-67.

17. Kovats RS, Hajat S, Wilkinson P. Contrasting patterns of mortality and hospital admissions during hot weather and heat waves in Greater London, UK. Occup Environ Med. 2004;61(11):893-898.

18. Wang XY, Barnett AG, Yu W, et al. The impact of heatwaves on mortality and emergency hospital admissions from non-external causes in Brisbane, Australia. Occup Environ Med. 2012;69(3):163-169.

19. Hajat S, Armstrong B, Baccini M, et al. Impact of high temperatures on mortality: is there an added heat wave effect? Epidemiology. 2006;17(6):632-638.

20. Schaffer A, Muscatello D, Broome R, Corbett S, Smith W. Emergency department visits, ambulance calls, and mortality associated with an exceptional heat wave in Sydney, Australia, 2011: a time-series analysis. Environ Health. 2012;11(1):3.

21. Turner LR, Connell D, Tong S. Exposure to hot and cold temperatures and ambulance attendances in Brisbane, Australia: a time-series study. BMJ Open. 2012;2:e01074.

22. Wang H, Matsumura M, Kakehashi M, Eboshida A. Effects of atmospheric temperature and pressure on the occurrence of acute myocardial infarction in Hiroshima City, Japan. Hiroshima J Med Sci. 2006;55(2):45-51.

23. Makie T, Harada M, Kinukawa N, et al. Association of meteorological and day-of-theweek factors with emergency hospital admissions in Fukuoka, Japan. Int J Biometeorol. 2002;46(1):38-41.

24. Abe T, Tokuda Y, Ohde S, Ishimatsu S, Nakamura T, Birrer RB. The relationship of short-term air pollution and weather to ED visits for asthma in Japan. Am J Emerg Med. 2009;27(2):153-159.

25. Bassil KL, Cole DC, Moineddin R, et al. The relationship between temperature and ambulance response calls for heat-related illness in Toronto, Ontario, 2005. J Epidemiol Community Health. 2010;65(9):829-831.

26. Dolney TJ, Sheridan SC. The relationship between extreme heat and ambulance response calls for the city of Toronto, Ontario, Canada. Environ Res. 2006; 101(1):94-103.

27. Alessandrini E, Zauli Sajani S, Scotto F, Miglio R, Marchesi S, Lauriola P. Emergency ambulance dispatches and apparent temperature: a time series analysis in Emilia-Romagna, Italy. Environ Res. 2011;111(8):1192-1200.

28. Cerutti B, Tereanu C, Domenighetti G, et al. Temperature related mortality and ambulance service interventions during the heat waves of 2003 in Ticino (Switzerland). Soz Praventivmed. 2006;51(4):185-193.
29. Nitschke M, Tucker GR, Bi P. Morbidity and mortality during heatwaves in metropolitan Adelaide. Med J Aust. 2007;187(11-12):662-665.

30. Nitschke M, Tucker GR, Hansen AL, Williams S, Zhang Y, Bi P. Impact of two recent extreme heat episodes on morbidity and mortality in Adelaide, South Australia: a case-series analysis. Environ Health. 2011;10:42.

31. Tong S, Wang XY, Barnett AG. Assessment of heat-related health impacts in Brisbane, Australia: comparison of different heatwave definitions. PLoS One. 2010;5(8):e12155.

32. Tong S, Wang XY, Guo Y. Assessing the short-term effects of heatwaves on mortality and morbidity in Brisbane, Australia: comparison of case-crossover and time series analyses. PLoS One. 2012;7(5):e37500.

33. Gasparrini A, Armstrong B. The impact of heat waves on mortality. Epidemiology. 2011;22(1):68-73.

34. Gasparrini A, Armstrong B, Kenward MG. Distributed lag non-linear models. Stat Med. 2010;29(21):2224-2234.

35. Barnett AG, Hajat S, Gasparrini A, Rocklov J. Cold and heat waves in the United States. Environ Res. 2012;112:218-224.

36. Semenza JC, McCullough JE, Flanders WD, McGeehin MA, Lumpkin JR. Excess hospital admissions during the July 1995 heat wave in Chicago. Am J Prev Med. 1999;16(4):269-277.

37. Kenny GP, Yardley J, Brown C, Sigal RJ, Jay O. Heat stress in older individuals and patients with common chronic diseases. CMAJ. 2010;182(10):1053-1060.

38. Worfolk JB. Heat waves: their impact on the health of elders. Geriatr Nurs. 2000;21(2):70-77.

39. Zhang Y, Nitschke M, Bi P. Risk factors for direct heat-related hospitalization during the 2009 Adelaide heatwave: a case crossover study. Sci Total Environ. 2012;442C:1-5.

40. Kovats RS, Ebi KL. Heatwaves and public health in Europe. Eur J Public Health. 2006;16(6):592-599.

41. Wong HT, Lai PC. Weather inference and daily demand for emergency ambulance services. Emerg Med J. 2012;29(1):60-64.

42. Vandentorren S, Bretin P, Zeghnoun A, et al. August 2003 heat wave in France: risk factors for death of elderly people living at home. Eur J Public Health. 2006; 16(6):583-591.

43. Abrahamson V, Wolf J, Lorenzoni I, et al. Perceptions of heatwave risks to health: interview-based study of older people in London and Norwich, UK. $J$ Public Health (Oxf). 2009;31(1):119-126.

44. O'Neill MS, Carter R, Kish JK, et al. Preventing heat-related morbidity and mortality: new approaches in a changing climate. Maturitas. 2009;64(2):98-103. 